\title{
INTERFACE ENTRE O SABER TÉCNICO E O SABER PEDAGÓGICO: PERCEPÇÕES NA NARRATIVA DO PROFESSOR
}

\section{MARIA RITA BARBOSA DE SOUSA}

Universidade Federal do Piauí / Colégio Técnico de Teresina

\section{MARIA DA GLÓRIA CARVALHO MOURA}

Universidade Federal do Piauí

O texto estrutura-se a partir das narrativas de professores com formação em Agronomia e Medicina Veterinária, em efetivo exercício da docência, no Curso Técnico em Agropecuária, um dos cursos do Colégio investigado identificado com práticas exitosas. O objetivo é analisar os saberes técnico e pedagógico dos professores do Curso Técnico em Agropecuária visando à compreensão da prática docente exitosa na educação profissional. Metodologicamente, optou-se pela abordagem qualitativa do tipo estudo de caso, tendo como principal instrumento de coleta de dados a entrevista narrativa. Os dados empíricos foram organizados em categorias, com base em Bardin (2011), e analisados à luz da análise do discurso, segundo Orlandi (2012; 2015). Os resultados revelam que a prática docente exitosa, no contexto semântico da Educação Profissional, se desenvolve em espaço favorável com instrumentos diversificados, propiciando a interação teórico-prática e despertando o interesse e a participação dos estudantes. Conclui-se que a prática aliada à teoria contribui para a realização de atividades docentes exitosas e consequentemente para a permanência e a aprendizagem dos estudantes.

Palavras-chave: Prática docente exitosa. Educação profissional. Saber técnico. Saber pedagógico.

\section{ABSTRACT INTERFACE BETWEEN TECHNICAL KNOWLEDGE AND PEDAGOGICAL KNOWLEDGE: PERCEPTIONS IN THE TEACHER'S NARRATIVE}

The text is structured from the teachers narratives with academic training in Agronomy and Veterinary Medicine in actual teaching exercice on the technical course in Agriculture, one of the courses of the investigated school with successful practices. Thus, the objec- 
tive is to analyze the technical and pedagogical knowledge of the teachers fron that technical course, aiming at the understanding of successful teaching practice in professional education. Methodologically it was chosen the qualitative approach by a case study type, using as main instrument of data collection the narrative interview. The empirical data were organized into categories based on Birdin (2011) and analyzed through discourse analysis according to Orlandi (2012 e 2015). The results highlight that the successful teaching practice in the semantic context of Professional Education develops in a propitious space with diversified tools, favoring the interection between theory-practice, arousing the interest and the participation of the students. It is concluded that practice associated with theory contributes to the achievement of successful teaching practices and, consequently to the students permanence and learning.

Keywords: Successful teaching practice. Professional education. Technical knowledge. Pedagogical knowledge.

\section{RESUMEN INTERFAZ ENTRE EL CONOCIMIENTO TÉCNICO Y EL CONOCIMIENTO PEDAGÓGICO: LA PERCEPCIÓN DE LA NARRATIVA DEL MAESTRO}

El texto se estructura a partir de las narrativas de profesores con formación en Agronomía y Medicina Veterinaria, en efectivo ejercicio de la docencia en el Curso Técnico en Agropecuaria, uno de los cursos del Colegio investigado identificado con prácticas exitosas. Así, el objetivo es analizar el saber técnico y el pedagógico de los profesores del Curso Técnico en Agropecuaria visando la comprensión de la práctica docente exitosa en la educación profesional. Metodológicamente optó por el enfoque cualitativo del tipo Estudio de Caso, teniendo como principal instrumento de recolección de datos la entrevista narrativa. Los datos empíricos se organizaron en categorías basadas en Bardin (2011) y se analizaron a la luz del análisis del discurso según Orlandi (2012 y 2015). Los resultados revelan que la práctica docente exitosa en el contexto semántico de la Educación Profesional se desarrolla en un espacio favorable con instrumentos diversificados, favoreciendo la interacción teoría-práctica, despertando el interés y la participación de los estudiantes. Se concluye que la práctica aliada a la teoría contribuye a la realización de prácticas docentes exitosas y consecuentemente para la permanencia y el aprendizaje de los estudiantes.

Palabras clave: Enseñanza práctica exitosa. La educación profesional. Conocimientos técnicos. Conocimiento pedagógico. 


\section{Introdução}

O desenvolvimento da prática pedagógica exitosa de professores com formação em Agronomia e Medicina Veterinária despertou o interesse em descobrir como o saber técnico e o saber pedagógico articulados contribuem com a concretização da prática docente exitosa. Para tanto, aborda-se o contexto de constituição e consolidação do ensino agrícola na rede federal, destacando sua gênese identitária e a transformação suscitada pela sociedade brasileira.

O ensino desenvolvido na Educação Profissional, inicialmente, privilegiava a aplicação do conhecimento empírico, dos denominados mestres de oficios. Com a consolidação deste trabalho, saberes e fazeres são construídos indicando as alternativas encontradas processualmente pelos professores para o alcance da prática docente bem-sucedida.

Assim, o presente estudo aconteceu em colégio técnico vinculado a uma Universidade Federal da Região Nordeste, o que permitiu analisar os saberes técnico e pedagógico dos professores do curso Técnico em Agropecuária, visando à compreensão da prática docente exitosa na educação profissional.

O embasamento profissional proporcionado pela perspectiva da prática docente exitosa é necessário aos profissionais da educação, tendo em vista que parte considerável das investigações no espaço escolar valoriza a dimensão do insucesso dos seus protagonistas, tornando essa prática desafiadora.

\section{O contexto de constituição e} consolidação do ensino agrícola na rede federal

No Brasil, difusão do ensino profissionalizante desenvolve-se por intermédio de dimensões como: repercussão social e capacidade de in- fluência na implantação de um modelo econômico, que se apresentam como meios que determinam a implantação, a consolidação, a descontinuidade e a continuidade das vivências, no desenvolvimento da educação profissional técnica no país.

A rede federal, concebida inicialmente como instrumento de política pública para as classes menos favorecidas, por meio das primeiras Escolas Técnicas, de acordo com Gonçalves (2013), surgiu com as Escolas de Aprendizes Artífices (EAA), instituídas pelo Decreto no 7.566 de 1909, assinado pelo presidente Nilo Peçanha, sob a jurisdição do Ministério dos Negócios da Agricultura, Indústria e Comércio. Foram criadas 19 escolas de Aprendizes de Artífices, em diferentes unidades federativas do país, a partir do que se consistiu na primeira política pública voltada para a modalidade.

As investigações no campo da Educação, ao considerarem a realidade contemporânea das escolas de ensino profissionalizante da rede federal, contribuem com a exclusão do estereótipo de educação voltada à classe menos favorecida, demarcada historicamente em sua implantação oficial, passando a se reconhecer, na educação profissional, a formação integral do indivíduo e o trabalho como princípio educativo, no interior das instituições de educação profissionalizante. Neste sentido, são finalidades da rede federal a oferta da educação profissional e tecnológica nos diferentes níveis e modalidades de ensino tendo em vista "[...], desenvolver a pesquisa aplicada, a inovação, a produção artística e cultural, o empreendedorismo, o cooperativismo, a extensão e o desenvolvimento científico e tecnológico entre outros" (BRASIL, 2014, p. 11).

O Decreto no 12.893, de 20 de fevereiro de 1918, do Ministério dos Negócios da Agricultura, Indústria e Comércio estimulou a tradição da formação agrícola, como afirma Azeredo (2010), com a autorização para a criação dos 
Patronatos Agrícolas em Postos Zootécnicos, fazendas-modelo de criação, núcleos coloniais, em outros estabelecimentos de ambiente e responsabilidade federal.

A criação dos Patronatos Agrícolas segue a perspectiva de atendimento ao legislado e às demandas das regiões. Houve, posteriormente, segundo Azeredo (2010), a vinculação de dois Patronatos Agrícolas às Universidades, como pioneiros: Visconde da Graça na cidade de Pelotas/RS, em 1923, e o Vidal de Negreiros na cidade de Bananeiras/PB, em 1924. No Estado do Piauí, somente em 1954 aconteceu o lançamento da pedra fundamental do Colégio Agrícola, mantido pela União e idealizado junto ao Estado.

$\mathrm{Na}$ análise particular das características de constituição da prática docente na Rede Federal de Nível Técnico, o ensino nas Escolas de Artífices acontecia em espaços como prédios e oficinas precárias, com os denominados mestres de ofícios que não tinham formação especializada para ministrar os cursos, visto que: “[...] faltava-lhes o conhecimento suficiente para atender aos requisitos de base teórica, que eram demandadas pelos cursos oferecidos. Assim sendo, a aprendizagem ficava restrita apenas ao conhecimento empírico" (LOPES, 2007, p. 213).

Assim, recrutavam-se profissionais com diversos saberes técnicos, justificando a ausência de base teórica nos cursos, privilegiandose a aplicação meramente do conhecimento empírico do mestre de ofício. Dessa forma, o corpo docente das escolas de Artífices constituía-se à medida que a necessidade nos cursos se manifestava.

O contexto atual das escolas técnicas vinculadas às universidades federais difere do período das escolas de Artífices, pois há docentes possuidores de formação profissional em nível de Pós-Graduação, stricto sensu e/ ou lato sensu, critérios recorrentes nos editais dos concursos para ingresso de professores em cursos técnicos profissionalizantes.

\section{Prática docente exitosa: saberes e fazeres pedagógicos}

A prática docente desenvolvida nos níveis e etapas de ensino aprimora-se por meio de saberes e fazeres constituídos ao longo da carreira dos professores, através de condicionantes empregados nas interações desenvolvidas pelos protagonistas da escola - professores e alunos, no processo de construção do conhecimento tendo como suporte básico o saber pedagógico, necessário ao desenvolvimento da prática docente, expressão simultânea desse saber e fonte de seu desenvolvimento. A compreensão da prática pedagógica que orientou o desenvolvimento deste estudo considera o professor como alguém que constrói saberes e reflete sobre seu trabalho no dia a dia da sala de aula.

[...] o professor, muitas vezes considerado um simples executor de tarefas, é alguém que também pensa o processo de ensino. Este Pensar reflete o professor enquanto ser histórico, ou seja, o pensar do professor é condicionado pelas possibilidades e limitações pessoais, profissionais e do contexto em que atua. (AZZI, 2002, p. 44)

Nesse sentido, esclarecemos que os saberes e fazeres a que nos referimos se diferenciam “[...] do conhecimento pedagógico, elaborado por pesquisadores e técnicos da educação", sendo construídos pelo professor (AZZI, 2002, p. 44). Os saberes pedagógicos são construídos pelo professor a partir das experiências vivenciadas no dia dia da sala de aula, tal como explicitado por Gauthier (2006), que os definiu como o repertório dos conhecimentos do ensino ou da jurisprudência pública validada pelos pesquisadores das ciências da educação e também pelos próprios professores (CARDOSO; PINO; DORNELES, 2012). 
Além dos saberes da ação pedagógica, existe o saber das ciências da educação e o saber da tradição pedagógica, inovações presentes nas pesquisas de Gauthier (2006) e Tardif (2002). A convergência dos estudos destes pesquisadores acontece nos saberes classificados como disciplinares, curriculares e experienciais, através do acréscimo do saber da formação profissional e do saber pessoal.

É sabido que o professor do ensino técnico, em sua prática docente, se apropria de saberes e fazeres pedagógicos, para adaptar-se às diversas situações educativas. Nesse sentido questiona-se: o que difere o saber de um fazer pedagógico?

A esse respeito, Franco (2009, p. 15) explica que "o fazer, decorrente do tratamento da prática, enquanto tecnologia será o exercício de uma ação mecânica, linear, inflexível, repetitiva". Em outras palavras, para a reprodução de um fazer, há ausência de articulação entre teoria e prática, de um sujeito pensante e reflexivo, restringindo-se, apenas, ao refinamento do exercício da prática.

Nesta diferenciação, o saber diverge do processo vivenciado no fazer, ao ser caracterizado como prática reflexiva e intencional. Franco (2009, p. 15) ainda complementa: “Os saberes decorrem da práxis social, histórica, intencionada, realizada por um sujeito histórico, consciente de seus determinantes sociais, em diálogo com suas circunstâncias".

A decorrência dos saberes e fazeres pedagógicos, no ensino técnico, no processo de constituição da prática docente para essa modalidade de ensino, historicamente, foi se constituindo a partir dos saberes práticos e que os, então, futuros professores possuíam. Nesta perspectiva adotada pelo senso comum, considerava-se, por exemplo, o engenheiro, ao saber de engenharia, apto a exercer a docência nos cursos de nível técnico da rede federal. Para essa posição argumentativa, Cardoso, Pino e Dorneles (2012), apoiados nos estudos de Gauthier (2006), partem da perspectiva que considera o exercício da docência como um 'ofício sem saberes'.

Isso significa dizer que o 'oficio sem saberes' se caracteriza pela prática dos professores em processo de descoberta da profissão docente, em que se atribui a estes os saberes técnicos de sua formação inicial, denominada durante muito tempo de oficio, subtendendose a ausência preliminar dos saberes pedagógicos, presentes na formação inicial dos professores licenciados.

A partir da consolidação da prática docente, desenvolvida em diversos eixos tecnológicos na rede federal, por meio dos cursos técnicos, o professor produtor de conhecimento denominado por Cunha (1996) como possuidor de prática pedagógica inovadora entra em contato com a necessidade de atendimento a alunos com perfis sociais variados, o que exige a complexidade da construção dos conhecimentos, para além da informação.

Pimenta (2002) atribui à prática docente a manifestação do saber pedagógico por meio de sua construção e desenvolvimento. Assim, reitera-se que os saberes pedagógicos adquirem espaço no contexto do ensino técnico profissional, tendo em vista os beneficios da conscientização do professor quanto à existência da práxis social e histórica em sua prática docente (FRANCO, 2008). Dessa forma, o processo de constituição dos saberes pedagógicos dos docentes do ensino técnico requer uma compreensão dos condicionantes que circunscrevem a construção de suas práticas.

É notório que as pesquisas sobre a prática docente exitosa, principalmente dos professores que atuam no ensino técnico profissionalizante, e articulam saberes técnicos e saberes pedagógicos, ainda são reduzidos. Ressalta-se a relevância destes, a fim de contemplar a interface entre o saber técnico e o saber pedagógico, em cursos de nível técnico. 
Em cursos de nível de Ensino Superior, Franco (2009), por exemplo, em um trabalho de análise das pesquisas a esse respeito, constatou que professores universitários trazem, como conceito dos saberes pedagógicos, pressupostos simplistas tais como o dom de ensinar, saber aplicar técnicas e métodos, saber transmitir conteúdos e sinônimo da atividade resultante de repetições dos procedimentos metodológicos. A autora referenciada, ao analisar os conceitos relativos aos saberes pedagógicos, declara que estes são compreendidos como prática social em construção, em que os vínculos imbricados dos sujeitos da prática e dos saberes pedagógicos são transformados de forma concomitante.

Assim, são considerados saberes que fundamentam a práxis docente, como também, simultaneamente, a prática docente expressa o saber pedagógico. Por práxis docente entende-se ser o conhecimento voltado para as relações sociais e as reflexões políticas, econômicas e morais. Considerando a interface do saber técnico ao saber pedagógico mobilizado pelo professor do ensino técnico, no processo de ensino e aprendizagem, faz-se necessária a compreensão dos condicionantes do processo de ensino e aprendizagem que circunscrevem a construção das práticas pedagógicas no contexto escolar.

Neste sentido, Haas et al $(2005$, p. 17$)$ propõem "uma reflexão em torno do diálogo, transitando pelas várias possibilidades que ele permite: diálogo como pressuposto interdisciplinar, como prática pedagógica, como condição para reflexão e ação do professor, como parceria". o diálogo como pressuposto interdisciplinar é considerado saber pedagógico, para a prática docente no ensino técnico, ao permitir que o professor e seus pares adotem uma prática pedagógica de interlocução com a realidade cotidiana, no espaço escolar, envolvendo o professor e o aluno durante o proces- so de desenvolvimento da aprendizagem.

Desta maneira, o sentido atribuído pelo docente ao diálogo, nas práticas realizadas em contexto escolar, envolve professor e aluno. Contudo, o professor do ensino técnico utiliza também o saber e o fazer pedagógico apoiado no diálogo com seus pares, professores possuidores de saberes técnicos semelhantes aos seus, que compartilham os mesmos desafios na formação acadêmica dos futuros técnicos, em campos diversos, como: comércio, indústria, agricultura e/ou serviços. São essas vivências que consolidam as práticas exitosas dos professores, nos cursos técnicos profissionalizantes.

0 benefício alcançado pelo professor, a partir do diálogo com os demais professores da sua equipe, possibilita que este "[...] reflita sobre sua ação, analise-a e a transforme. Essa reflexão the permitirá manter-se no caminho em que se encontra ou buscar outros, no seu fazer pedagógico [...] resgatar suas ações, revê -las e aprender com elas, levando-o à autoformação permanente" (HAAS et al, 2005, p. 37).

Além do diálogo, destaca-se como condicionante do saber e fazer pedagógico, no processo de aprendizagem dos adolescentes, o fato de que os conhecimentos utilizados são resultados dos esforços de estudiosos da aprendizagem, que desvendaram os processos de desenvolvimento de habilidades e potenciais da formação de pessoas, como também da resolução de problemas educacionais (VALLE, 2015).

Desse modo, o Sistema de Ensino Agrícola da rede federal consolidou-se sofrendo considerável influência norte-americana, nos anos de 1950 do século XX, com atividades envolvendo uma rede de agentes e agências, representando interesses político-econômicos da época. São períodos importantes da constituição do ensino agrícola brasileiro, ou seja, estabeleceu-se uma reforma que propusesse 
a relação entre educação e desenvolvimento (BRANCO, 2010).

O saber técnico e o saber pedagógico agrícola é constituído em modelos escolares diversos, entre eles: Escolas de Iniciação Agrícola, Patronatos, Escolas Agrotécnicas e Colégios Agrícolas, conforme Azeredo (2010). A política para o ensino agrícola, na década de 1970, implantada pela Coordenação Nacional de Ensino Agropecuário (COAGRI), volta-se para o modelo escola-fazenda, baseado no princípio do aprender a fazer fazendo, o que trouxe influências marcantes para a práticas educativas.

A prática pedagógica fundamentada nos princípios e pressupostos da COAGRI permitia aos professores desenvolverem sua metodologia de trabalho levando os estudantes a fazerem da experiência do trabalho, na denominada Cooperativa-Escola, um elemento essencial de organização da instituição de ensino na formação de técnicos em Agropecuária.

Tendo em vista a importância da Cooperativa-Escola dentro do Sistema Escola-Fazenda, desenvolviam-se projetos durante o ano correspondentes às disciplinas cursadas pelos estudantes; tratava-se assim da composição do currículo do ensino agrícola brasileiro na esfera federal. As atividades diversas, descritas no Relatório Geral de 1982, destacam, como procedimentos, a participação do educando nos projetos de subsistência do produtor rural, desenvolvidos por técnicos da EMATER local (BRASIL, 1982). Nesta linha de argumentação, a formação do técnico em Agropecuária da esfera federal, baseada em projetos de extensão rural, estabelecia-se concomitante ao trabalho dos técnicos da EMATER junto aos produtores rurais.

O documento elaborado por representantes dos profissionais das instituições de ensino agrícola federal e membros da Secretaria de Educação Profissional (SETEC), no ano de 2009, durante os Seminários Regionais e $\mathrm{Na}$ - cionais de Re(significação) do Ensino Agrícola, demonstra, no registro das deliberações da plenária final, a presença, na contemporaneidade, das práticas educativas mobilizadas pela COAGRI na política para o ensino agrícola implantada na década de 1970.

A política para o ensino agrário, implantada pela COAGRI (BRASIL, 2009, p. 11), "foi responsável por sistematizar e padronizar estratégias pedagógicas e de gestão dando uma identidade única a esta modalidade de ensino, e pelo equipamento das escolas, para um ensino em sintonia com as tecnologias preconizadas pela Revolução Verde". Por Tecnologia da Revolução Verde compreende-se o propósito do crescimento a produção através do desenvolvimento de sementes, fertilização do solo e utilização de máquinas no campo que pudessem aumentar a produção.

A prática pedagógica implantada no ensino agrícola pela COAGRI, na década de 1970, é apresentada no Relatório Geral (BRASIL, 1982). A normatização da COAGRI para o ensino agrícola da rede federal é inovadora para a época, ao trazer para o interior dos colégios agrícolas brasileiros a Cooperativa-Escola, centro da metodologia do Sistema Escola-Fazenda, modificando a estrutura fisica das instituições e a prática de seus professores.

Outra inovação foi envolver os estudantes por meio de um calendário de atividades próprias para fins de participação nos projetos do sistema Escola-Fazenda. As escolas agrícolas da rede federal realizavam assistência estudantil de moradia que, com o planejamento do currículo integral nos cursos técnicos, contribuía com a concretização desse diferencial no ensino dos futuros técnicos agrícolas.

Em síntese, o Relatório Geral da COAGRI descreve as experiências pedagógicas desenvolvidas nas Escolas Agrícolas Familiares, a partir da integração dos colégios agrícolas à comunidade local, o que colocava o futuro téc- 
nico em atividades práticas de acordo com o perfil do curso. Os estudantes contavam com atividades pedagógicas que desenvolvessem seu potencial individual e coletivo, na convivência com seus colegas de turma e professores, aprimorando habilidades sociais, culturais e cognitivas.

Os saberes e fazeres pedagógicos inseridos no eixo tecnológico Recursos Naturais, especificamente no Curso Técnico em Agropecuária, consideram os modelos agrícolas de produção distintos, entre eles: modelo da atividade agropecuária familiar individual ou organizada pelo associativismo, o modelo oposto, denominado do grande capital presente na agricultura e na pecuária, além do recente movimento do modelo de produção sustentável (SOBRAL, 2009).

\section{Aspectos Metodológicos}

O estudo foi alicerçado nos pressupostos da pesquisa qualitativa do tipo estudo de caso. Ao assumir essa perspectiva teórico-metodológica, os significados múltiplos das experiências individuais, significados social e historicamente construídos, são elementos observáveis nesta pesquisa.

Desse modo, os procedimentos metodológicos da técnica do estudo de caso apresentam-se como ferramenta mobilizadora de uma ampla possibilidade de desenvolvimento do trabalho investigativo através dos locais e possiveis participantes considerados objeto do estudo ou fonte de dados, razão pela qual se prioriza a necessidade da avaliação do lócus e das fontes de dados, tendo como parâmetro os objetivos (BOGDAN; BIKLEN, 1994).

$O$ estudo foi estruturado a partir das narrativas de professores com formação em Agronomia e Medicina Veterinária, em efetivo exercício da docência no Curso Técnico em Agropecuária, eixo tecnológico Recursos Naturais, por ser este, segundo os documentos oficiais do colégio técnico pesquisado, considerado como um dos cursos com práticas exitosas.

A entrevista narrativa foi escolhida como estratégia de investigação para a recolha de dados, pois, ao longo deste estudo, foram vivenciados os temas apresentados pelos participantes, a partir das informações produzidas. Gaskell (2002) enfatiza que a narrativa permite aos participantes do estudo ações diversas, entre elas: lembrar o que aconteceu e colocar a experiência em uma sequência, além de encontrar possíveis explicações para isso, vivenciando as teias de acontecimentos que constroem a vida individual e social.

Continuando, Bertaux (2010, p. 27) diz: “[...] essa forma de coleta de dados empíricos se ajusta à formação das trajetórias; ela permite identificar por meio de que mecanismos e processos os sujeitos chegaram a uma dada situação, como se esforçam para administrar essa situação e até mesmo para superá-la". Nesse contexto, a entrevista se aplicou ao nosso objeto de estudo, para, entre outras finalidades, possibilitar ao pesquisado oferecer as informações de forma espontânea, garantindo fidedignidade à investigação.

Por isso, ao utilizar a entrevista narrativa como instrumento desta investigação, o relato da prática docente exitosa na Educação Profissional fluiu com naturalidade, na visão e voz dos professores do Curso Técnico em Agropecuária, permitindo a análise dos saberes técnico e pedagógico. Considerou-se a importância da influência mínima do entrevistador, como também do ambiente preparado para tal fim (GASKELL, 2002).

Nesta pesquisa, foram consideradas ainda três fases principais, reconhecidas por Gaskell (2002), na entrevista narrativa. Na primeira, o foco concentrou-se na experiência do informante. Na segunda, o papel de investigador restringiu-se à escuta ativa, ao apoio não verbal ou paralinguístico. Toda a atenção devida foi ma- 
nifestada pelo investigador deste estudo, nesta segunda fase, por estar consciente de ser o momento da narração central, ou seja, o ápice da produção de informações disponibilizadas pelos participantes. Nesta fase, o entrevistado foi incentivado pelo pesquisador a socializar suas concepções e experiências. Por fim, a terceira fase sinalizou o fechamento das contribuições do entrevistado, isto é, a síntese conclusiva de seus pensamentos sobre o objeto investigado.

A entrevista narrativa possui como elemento estruturante "[...] a utilização de uma 'pergunta gerativa narrativa' [...] que se refere ao tópico de estudo e que tem como finalidade estimular a narrativa principal do entrevistado" (FLICK, 2009, p. 165). Neste estudo, a pergunta gerativa narrativa adotada foi dividida em dois momentos distintos: o primeiro constou de uma questão gerativa sobre as impressões dos participantes relacionadas com as práticas consideradas exitosas, no contexto semântico da educação profissional.

No segundo momento, a questão gerativa voltou-se para a trajetória de vida e profissional dos participantes e reflete as interfaces entre o saber técnico e o saber pedagógico voltadas para o desenvolvimento de sua prática. Em ambos, a entrevista foi gravada, portanto, o que foi dito pelo interlocutor da investigação foi registrado nas transcrições do investigador, para posterior estudo.

A entrevista narrativa, nesse estudo, desenvolveu-se, também, a partir da técnica da amostragem não probabilística, bola de neve (DEWES, 2013), uma técnica na qual os próprios participantes, ao serem investigados, indicaram, no final da entrevista narrativa, um colega de trabalho considerado pelo participante como alguém que desenvolve prática exitosa. A denominação "bola de neve" significa dizer que as informações produzidas vão crescendo à medida que agregam as ideias dos novos participantes convidados.
Segundo Dewes (2013), a aplicação do método da amostragem não probabilística "bola de neve" divide-se em passos. O primeiro, fundamental para a confiabilidade do resultado da pesquisa, é encontrar a população-alvo que faz a diferença, foco do estudo, e que é denominada semente da amostra.

No segundo passo, o processo bola de neve foi iniciado com os participantes classificados como sementes, através da onda zero. Nesta pesquisa, a sucessão das denominadas ondas é considerada sempre a partir da onda zero.

Em suma, Dewes (2013) esclarece que cada semente indica o contato com outro indivíduo que ele considere membro da população-alvo do estudo. A sucessão de ondas fica assim denominada: onda um, formada pelos contatos indicados pelos indivíduos da onda zero que fazem parte da população-alvo e que não fazem parte da onda zero; a onda dois, por sua vez, é formada pelos contatos indicados pelos indivíduos da onda um, que fazem parte da população-alvo e que não fazem parte da onda zero e da onda um.

A sucessão das ondas permitiu compreender a característica da amostragem linear não probabilística do método bola de neve. A dinâmica do processo seguiu até que as informações produzidas respondessem à questão/ problema da pesquisa, atingindo os objetivos previstos.

O critério para a escolha dos participantes, sementes da amostra, nomeados neste trabatho de onda zero, foi estabelecido, inicialmente, por meio dos dados funcionais do Sistema Integrado de Gestão de Recursos Humanos (SIGRH), dos professores do curso investigado com maior quantitativo de tempo na carreira de efetivo exercício do Magistério no curso de Técnico em Agropecuária.

Foram entrevistados nove participantes, a fim de garantir a fidedignidade das informações produzidas (Gráfico 1). 
Gráfico 1 - Participantes: Semente/Onda zero, Onda um e Onda dois

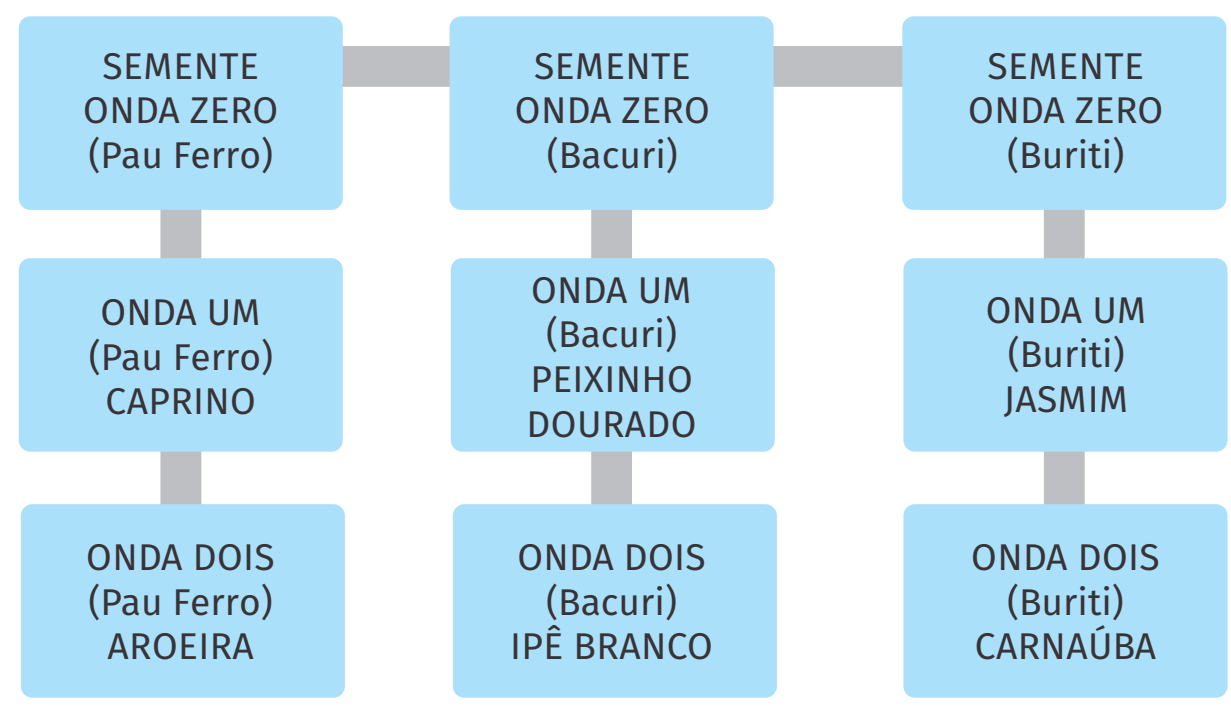

Fonte: Organizado pela pesquisadora (2016).

Depois da realização do levantamento dos dados empíricos, estes foram organizados em categorias gerais e unidades de registro, “[...] um agrupamento de elementos que são sistematizados pelo pesquisador(a) após a pesquisa de campo" (OLIVEIRA, 2007, p. 93), para facilitar a análise. o processo de categorização possui como princípios “operação de classificação de elementos constitutivos de um conjunto por diferenciação e, seguidamente, por rea- grupamento segundo o gênero (analogia), com os critérios previamente definidos" (BARDIN, 2011, p. 145).

Evidentemente, as “[...] categorias não são definidas a priori emergem da 'fala', do discurso, do conteúdo das respostas e implicam constante ida e volta do material de análise à teoria" (FRANCO, 2008, p. 60). Assim, na presente investigação, as informações foram organizadas em Categorias e Unidades de Registros, como definidas no Gráfico 2.

Gráfico 2 - Categorização dos dados

CATEGORIA GERAL 01: Prática diferenciada desperta
o interesse e a participação do aluno: concepção dos
professores
Unidade de Registro 1.1 - Visão pedagógica: dificuldades
Unidade de Registro 1.2 - Compromisso e experiência profissional
Unidade de Registro 1.3 - Vivenciar a prática, aliada a teoria

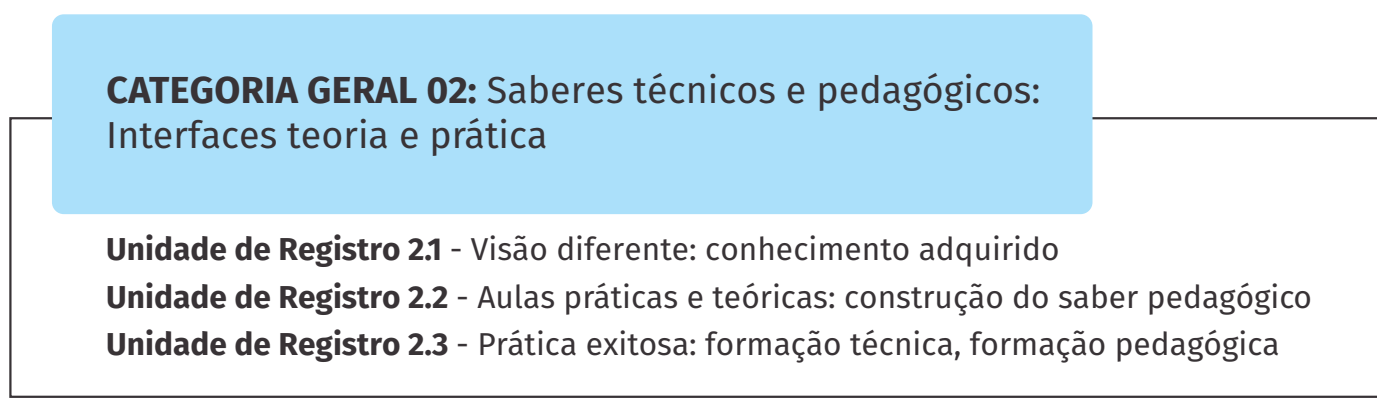

Fonte: Organizado pela pesquisadora, tendo como referência as informações produzidas no campo empírico (2016). 
As categorias gerais foram construídas a partir do núcleo de sentido presente na fala dos interlocutores; as unidades de registro compreenderam a significação codificada em trechos pequenos, para facilitar a análise, visando responder a questão/problema que norteou o estudo: "como os saberes técnico e pedagógico articulados contribuem para uma prática docente exitosa no contexto semântico da Educação Profissional, no curso Técnico em Agropecuária?"

A análise interpretativa das contribuições advindas do campo empírico foi realizada à luz da análise do discurso, constituindo-se em informações povoadas de sentidos e significados histórico-sociais, expressas na voz dos interlocutores, colaboradores da investigação (ORLANDI, 2012).

$\mathrm{Na}$ interlocução com os professores, foram obtidos subsídios que nos permitem afirmar que a prática docente exitosa na educação profissional é possivel de ser realizada, em um contexto semântico diversificado, necessitando: de uma teoria que the dê sustentação, de um espaço com condições favoráveis para o êxito de sua realização, e de ferramentas e/ou recursos que viabilizem sua execução.

\section{Resultados alcançados}

A construção de práticas docente exitosas no contexto da educação profissional encontra no discurso dos professores do Curso Técnico em Agropecuária, participantes deste estudo, o sentido e significado de uma educação que prima pela qualidade no contexto semântico da educação profissional. Mas por que semântico? Freire (2000, p. 63), sabiamente nos lembra, que: A palavra, a frase, o discurso articulado não se dão no ar. São históricos e sociais - e sutilmente nos oferece elementos que validam a argumentação da sua construção tendo como determinante o saber teórico articulado aos saberes práticos, ambos adquiridos e consolidados na teorização vivenciada no contexto da educação profissional.

Com efeito, a prática pedagógica não acontece no ar, mas se realiza em um contexto semântico diversificado, visto que, para ser desenvolvida, necessita de uma teoria que the dê sustentação, de um espaço em condições favoráveis para o êxito de sua realização, bem como de ferramentas e/ou recursos que facilitem sua execução.

Ressalta-se a importância do estudante e do professor, o qual fará a mediação inter-relacionando a tríade: saber teórico, saber prático e o contexto semântico, onde a ação se realiza. Razão pela qual o diálogo entre a teoria e prática [...] São históricos e sociais. Para efeito deste texto analisamos apenas um grupo de falas 01, 02 e 03, que acreditamos expressar a prática exitosa no Curso Técnico em Agropecuária de um colégio de Ensino Básico, Técnico e Tecnológico, vinculado à Universidade Federal da região Nordeste. Passemos à análise.

01 - O Colégio não tinha Pedagogo. Existia na Coordenação Pedagógica uma pessoa de confiança do Diretor. Fui escolhido, sou Engenheiro Agrônomo. Em um encontro de coordenadores os colegas que ocupavam essa pasta eram Pedagogos. Discutiam e nós Engenheiro Agrônomo, ou Médico Veterinário que estava exercendo aquele papel, não tínhamos o embasamento pedagógico. Fazia as reuniões, que o MEC pedia, mas tínhamos dificuldades. Senti a necessidade de melhorar o meu trabalho. No Mestrado, cursei Metodologia e Prática do Ensino em função do momento que a gente vivia dentro das escolas. Melhorei me senti um verdadeiro professor. Apenas duas disciplinas do curso de Pedagogia, mostrava o que era o professor técnico e o professor com visão pedagógica. Isso me fez crescer, a qualidade de minhas aulas melhorou, sentia nas respostas dadas pelos alunos. Eu, técnico envaidecido sabia fazer no campo, mais ensinar a fazer fazendo, essa é a diferença. A área pedagógica nos mostrou uma nova visão das práticas de ensino. Sinto-me outra pessoa, 
por ter participado dessa construção pedagógica. O êxito que eu posso citar é... O PROEJA, voltado para jovens e adultos e que o colégio implantou no curso de Agropecuária. (Semente Bacuri, Onda "0").

2 - Cheguei com perspectivas... Tive dificuldades tratava os alunos como se eles já soubessem... Fui buscando a linguagem deles e diferenciando minhas aulas, para não ficar somente na exposição... Realizava debates, elaborava relatórios e desenvolvia as práticas. A prova fazia muito extensa, eles achavam o nivel elevado. Fui percebendo e aprendendo a repassar o conhecimento valorizando a experiência... As primeiras turmas...a maioria, vinham do interior, hoje são mais urbanos... Fui aprendendo a conhecer a história de cada um... Hoje, boa parte segue curso superior, isso é gratificante. Acho exitoso o trabalho, os experimentos, os estágios, eles se envolvem bastante querem aprender. (Jasmim, Onda 01: Semente, Buriti)

3 - Situações onde se tem uma percepção clara que o conteúdo transmitido e objetivo foram alcançados, em nível educacional e técnico, prático e pessoal, utilizado pelo aluno no dia a dia, considera-se uma prática exitosa. Na parte técnica fica claro o que ele entendeu pela participação e interesse. Tiveram situações que marcaram: interagir e despertar o interesse do aluno e das pessoas da comunidade com relação ao aproveitamento dos conhecimentos por ele adquirindo. $O$ ingresso mudou... $O$ aluno está mais urbano e isso o distância do curso de Agropecuária. 0 aluno vem com objetivo diferente daqueles que vem para fazer só o técnico... Esses objetivam adquirir conhecimento e usar no futuro. A atividade individual do professor é importante, fazendo a sua parte contribui para que o aluno se interesse mais. Vejo assim a prática docente... Essas experiências exitosas dão animo para o professor ir melhorando... Embora cíclica, as turmas são heterogêneas num momento ruim e de repente vem uma melhor. (Aroeira, onda 02: Semente, Pau Ferro)

Ao analisar as dificuldades relacionadas com a área pedagógica do Curso Técnico em Agropecuária, Semente Bacuri, Onda "0", deixa claro que sendo a formação do professor, em Agrono- mia ou Medicina Veterinária: [...] não tínhamos o embasamento pedagógico. Na sua fala, enfatiza a necessidade do apoio de um profissional da área de Pedagogia para assessoramento da coordenação dos cursos técnicos.

$\mathrm{Na}$ condição de coordenador pedagógico, este profissional reconhece a importância dos conhecimentos pedagógicos para o desempenho de suas atividades, o que foi buscar em cursos de formação continuada. Isso ficou evidente, quando afirma: [...] cursei Metodologia e Prática de Ensino, cujo aprendizado [...] mostrava o que era o professor técnico e o professor com visão pedagógica, ajudando-o a superar suas dificuldades.

Assim, o domínio das questões pedagógicas presentes no desenvolvimento de ações realizadas no cotidiano da sala de aula é reconhecidamente fundamental para a concretização de práticas docente exitosas dos professores da área específica, Médicos Veterinários e Agrônomos. A superação das dificuldades orientadas por pedagogos mobiliza saberes adquiridos na formação inicial, na formação continuada e nas práticas realizadas fora do espaço da sala de aula.

A formação direcionada para a prática pedagógica despertou em Semente Bacuri, Onda ' 0 ”, o sentimento de ter se tornado [...] outra pessoa, por ter participado dessa construção pedagógica. Expressa, assim, o quanto a visão pedagógica ampliada contribuiu para o seu crescimento pessoal e profissional. Esse indicativo da procura individual por formação continuada, pelo professor da Educação Profissional, resulta em práticas docente exitosas pelo acúmulo de saberes decorrentes “[...] da práxis social, histórica, intencionada, realizada por um sujeito histórico, consciente de seus determinantes sociais, em diálogo com suas circunstâncias" (FRANCO, 2009, p. 15).

Nesse sentido, o reflexo da formação continuada se faz sentir, no desenvolvimento 
pessoal e profissional dos professores, mediante reflexões individuais sobre sua própria prática, transformando-se na busca de solução para situações problemáticas que surgem no contexto da sala de aula e no campo de vivência dos estudantes em formação (IMBERNÓN, 2010).

Para Jasmim - Onda 01: Semente, Buriti, as dificuldades enfrentadas, no início de sua experiência profissional como docente, direcionam-se para a compreensão do conhecimento e das relações interpessoais que foram gradativamente sendo construídas no dia a dia, por meio das atividades realizadas no Curso Técnico em Agropecuária. Inicialmente, afirma: [...] tratava os alunos como se eles já soubessem... Contudo, as alternativas encontradas para solucionar essas dificuldades vieram com o passar do tempo [...] buscando a linguagem deles [...] percebendo e aprendendo a repassar o conhecimento. Sabe-se que o trabalho do professor é prático, dinâmico, e exige um constante repensar sobre o seu fazer. Sendo assim, ao deparar-se com as suas dificuldades, reinventa e cria mecanismos para superá-las.

Ao reconhecer que foi se percebendo um profissional à medida que ia compreendendo as relações que se estabelecem no contexto semântico da escola, no caso específico, da Educação Profissional, nota-se que Jasmim fez uma reflexão sobre a sua ação pedagógica, o que Haas et al (2005, p. 20) chamaram de "o diálogo consigo mesmo", que consiste no repensar do seu fazer docente, oferecendo-lhe "[...] condições de organizar e sistematizar a compreensão de sua ação". Essa reflexão ocasionou mudanças relevantes em sua postura frente às relações estabelecidas entre professor, estudantes e conhecimento, tríade basilar para a prática exitosa na escola.

Então, a segurança necessária à ação do professor da Educação Profissional, segundo Jasmim, pauta-se na [...] experiência; na ca- pacidade de [...] conhecer a história de cada um...visto que o desenvolvimento do trabalho docente que busca a qualidade na educação deve partir dos saberes que os estudantes já trazem, considerando que a aprendizagem significativa se pauta em aspectos relacionados à individualidade do aprendente, reconhecendo-o como um sujeito em formação, portanto, inacabado. "Na verdade, o inacabamento do ser ou sua inconclusão é próprio da experiência vital. Onde há vida, há inacabamento" (FREIRE, 2002, p. 55).

Aroeira - Onda 02: Semente/Pau Ferro aponta como dificuldade maior despertar os estudantes para o curso Técnico em Agropecuária, considerando que a demanda existente está constituída por estudantes do meio [...] urbano e isso distancia do curso de Agropecuária o público proveniente do meio rural. Essa realidade acrescenta mais um desafio ao trabaIho docente: relacionar o contexto semântico do estudante com o contexto do Curso Técnico em Agropecuária, pois é natural que os laços afetivos do estudante estejam relacionados ao seu espaço de vivência.

O espaço urbano é a sua âncora, o seu mundo. Esta âncora influencia suas decisões, seja no sentido de resistir ou de aceitar o que Ihe está sendo proposto. Em qualquer uma das opções, o professor precisa estar atento para não transformar o contexto semântico da Educação Profissional em um contexto em que o estudante é “[...] treinado, adestrado, 'aprende' a sobreviver, a caçar, a atacar, a defenderse num tempo de dependência dos adultos imensamente menor do que é necessário ao ser humano para as mesmas coisas" (FREIRE, 2002, p. 56).

Nesse sentido, requer do docente a mobilização de saberes pedagógicos que o tornem capaz de intervir no processo educativo recriando ações de intervenção que possibilitem a aprendizagem significativa, consciente que 
ambos, professor e estudante, são seres inacabados, portanto, em formação. Ressalte-se que a dinâmica histórica, social e econômica assumida pelos modelos escolares do ensino agrícola brasileiro tem suas raízes relacionadas ao perfil da educação rural.

Aroeira destaca, ainda, que [...] as turmas são heterogêneas, num momento ruim e de repente vem uma melhor. Refletindo sobre o não dito em seu discurso, essa situação influencia o êxito da prática docente. No entanto, tal característica não se constitui em fator determinante para o êxito ou não da prática pedagógica. Turmas heterogêneas sempre vão existir, pois temos consciência de que estamos lidando, não somente com pessoas, mas com pessoas no mundo do contexto semântico da Educação Profissional. Reflitamos: "O fato de me perceber no mundo, com o mundo e com os outros me põe numa posição em face do mundo que não é de quem nada tem a ver com ele [...]. É a posição de quem luta para não ser apenas objeto, mas sujeito também da história" (FREIRE, 2002, p. 60).

De um modo geral, a prática docente exitosa, no contexto da educação profissional, está presente na fala dos professores, deixando claro que "É no cenário profissional que se aplicam as regras da prática, em que o conhecimento profissional imaginário, intuitivo ou formal se torna real e explícito" (IMBERNÓN, 2010, p. 71).

\section{Considerações finais}

A prática exitosa na Educação Profissional estrutura-se nos rigores da ciência e demanda a mobilização de saberes heterogêneos que consideram a singularidade das escolhas dos professores, feitas de acordo com os paradigmas da Educação, sejam conservadores (reprodutores do conhecimento) e/ou inovadores (produtores do conhecimento).
Ao adotar a formação permanente do professor, a escola avança para o paradigma da prática pedagógica emergente, ultrapassando a visão uniforme e assumindo uma visão de rede, de teia de interdependência dos profissionais do ambiente escolar, segundo Behrens (2010). A reflexão a respeito da formação técnica e da formação pedagógica demonstra a amplitude dos saberes que os professores da Educação Profissional cotidianamente entram em contato, resultantes da convivência com seus pares.

A análise dos saberes técnico e pedagógico dos professores do Curso Técnico em Agropecuária permitiu a compreensão da prática docente exitosa na educação profissional, compreendendo-a como uma prática pedagógica fundamentada em saberes pedagógicos e que prioriza as necessidades de aprendizagem dos estudantes.

Os resultados alcançados indicam, em consideração ao desenvolvimento da articulação dos saberes técnico e pedagógico na instituição investigada, a necessidade da implantação de grupo de estudos, conforme o interesse dos professores, pela pedagoga lotada no colégio, com temáticas que envolvam o processo de ensino- aprendizagem e com fundamentos na Psicologia do desenvolvimento e nas Ciências cognitivas, favorecendo a construção de práticas docentes exitosas coletivas, no contexto semântico da educação profissional no lócus do curso investigado.

Os docentes, no desenvolvimento da prática pedagógica, de acordo com a necessidade de atuação e os objetivos que desejam atingir, constroem, reconstroem, mobilizam e sistematizam saberes, não se tornando repetidores de conteúdos e técnicas, mas indivíduos que avaliam e reformulam continuamente a sua prática. A formação permanente dos professores experientes e dos iniciantes, em um grupo de estudo, permite um equilíbrio entre os sabe- 
res construídos nas Universidades e os saberes produzidos na prática cotidiana do colégio em que os participantes desenvolvem seu trabalho.

Com o exposto, acredita-se como necessária a ampliação das investigações sobre os conhecimentos, a formação permanente dos professores, iniciantes e experientes, da Educação Profissional, buscando seu fortalecimento nas pesquisas da Academia e no ambiente escolar, e proporcionando uma reflexão sobre as contribuições da formação continuada na escola de ensino médio de tempo integral, como é o caso do colégio técnico pesquisado. Além disso, investigar as práticas pedagógicas e o currículo e, com isto, chamar a atenção para a importância do diálogo entre os saberes técnicos e pedagógicos e sua relação com as práticas exitosas que se constituem no interior da escola, contribuindo não só com o debate em torno do tema, mas com sugestões de aperfeiçoamento das políticas de formação continuada para os professores e técnicos que atuam na Educação Profissional.

\section{Referências}

AZEREDO, Genival Alves de. Escolas técnicas vinculadas às universidades federais: uma breve história. In: MOLL, Jaqueline. (Org.). Educação profissional e tecnológica no Brasil contemporâneo: desafios, tensões e possibilidades. Porto Alegre: Artmed, 2010. p. 207-219.

AZZI, Sandra. Trabalho docente: autonomia didática e construção do saber pedagógico. In: PIMENTA, Selma Garrido. (Org.). Saberes pedagógicos e atividade docente. 3. ed. São Paulo: Cortez, 2002. p. 35- 60. BARDIN, Laurence. Análise de conteúdo. 4. ed. São Paulo: Edições 70, 2011.

BEHRENS, Marilda Aparecida. 0 paradigma emergente e a prática pedagógica. 4. ed. Petrópolis, RJ: Vozes, 2010.

BERTAUX, Daniel. Narrativas de vida: a pesquisa e seus métodos. Natal: EDUFRN; São Paulo: Paulus, 2010.
BOGDAN, Roberto C.; BIKLEN, Sari. Investigação qualitativa em educação: uma introdução à teoria e aos métodos. Porto: Porto Editora, 1994. p. 89-108.

BRANCO, Julinete Vieira Castelo. Entre trilhas e veredas. Teresina: Fundação Cultural Monsenhor Chaves, 2010.

BRASIL. Ministério de Estado da Agricultura, Indústria e Comércio. Diário Oficial da União - Seção 1 25/7/1918, Página 9728. (Publicação Original)

Ministério da Educação. Relatório Geral 1982 da COAGRI. Brasília, DF: MEC, 1982.

Ministério da Educação. (Re)significação do

Ensino Agrícola da Rede Federal de Educação Profissional e Tecnológica. Documento Final, BrasíliaDF, abril de 2009.

Documento Orientador para superação da evasão e retenção na rede federal de educação profissional, científica e tecnológica. Brasília, DF: MEC, SETEC 2014. Disponivel em: <http://www.ifto. edu.br/portal/docs/proen/doc_orientador_evasao_retencao_setec.pdf>.Acesso em: 16 mai. 2016.

CARDOSO, Aliana Anghinoni; PINO, Mauro Augusto Burkert Del; DORNELES, Caroline Lacerda. Os saberes profissionais dos professores na perspectiva de Tardif e Gauthier: contribuições para o campo de pesquisa sobre os saberes docentes no Brasil. In: SEMINÁRIO DE PESQUISA EM EDUCAÇÃO DA REGIÃO SUL, ANPEd SUL - A Pós-Graduação e suas interlocuções com a Educação Básica, 9., 2012, Caxias do Sul. Anais... Caxias do Sul: Associação Nacional de Pós-Graduação e Pesquisa em Educação - ANPEd, 2012. Disponivel em: <http://www.ucs.br/etc/conferencias/index.php/anpedsul/9anpedsul/paper/ viewFile/668/556>. Acesso em: 02 abr. 2016.

CUNHA, Maria Isabel da. Ensino com pesquisa: a prática do professor universitário. Caderno de Pesquisa, São Paulo, n. 97, p. 31-46, 1996.

DEWES, João Osvaldo. Amostragem em bola de neve e respondent-drivensampling: uma descrição dos métodos. 2013. 53 f. Trabalho de Conclusão de Curso (Monografia apresentada para obtenção do grau de Bacharel em Estatística) - Instituto de Matemática e Estatística, Universidade Federal do Rio Grande do 
Sul, Porto Alegre, 2013.

FLICK, Uwe. Introdução à pesquisa qualitativa. Porto Alegre: Artmed, 2009.

FRANCO, Maria Amélia Santoro. Prática docente universitária e a construção coletiva de conhecimentos: possibilidades de transformações no processo ensino-aprendizagem. Cadernos de Pedagogia Universitária 10. São Paulo: Universidade de São Paulo; Pró-Reitoria de Graduação, setembro de 2009.

FRANCO, Maria Laura Publisi Barbosa. Análise de conteúdo. 3. ed. Brasília, DF: Líber Livro Editora, 2008.

FREIRE, Paulo. A educação na cidade. 4. ed. São Paulo: Cortez, 2000.

Pedagogia da autonomia: saberes necessários à prática educativa. São Paulo: Paz e Terra, 2002.

GASKELL, George. Pesquisa qualitativa com texto, imagem e som: um manual prático. Petrópolis, RJ: Vozes, 2002.

GAUTHIER, Clermont et al. Por uma teoria da pedagogia: pesquisas contemporâneas sobre o saber docente. 2. ed. Ijuí, RS: Editora Unijuí, 2006.

GONÇALVES, Harryson Júnior Lessa. Das escolas de aprendizes artífices à Reforma Capanema. Revista Iluminart, ano V, n. 10, p. 25-41, jun. 2013.

HAAS, Celia Maria et al. O sentido do diálogo na prática educativa In: PETEROSSI, Helena Gemignani; MENESES, João Gualberto de Carvalho. (Coords.). Revisitando o saber e o fazer docente. São Paulo: Pioneira Thomson Learning, 2005. p. 17-42.
IMBERNÓN, Francisco. Formação docente e profissional: formar-se para a mudança e a incerteza. 8. ed. São Paulo: Cortez, 2010.

LOPES, Eliane Marta Teixeira. (Org.). 500 anos de educação no Brasil. 3. ed. Belo Horizonte: Autêntica, 2007.

OLIVEIRA, Maria Marly de. Como fazer pesquisa qualitativa. Petrópolis, RJ: Vozes, 2007.

ORLANDI, Eni Pulcinelli. Discurso em análise: sujeito, sentido e ideologia. Campinas, SP: Pontes Editores, 2012.

Análise de discurso: princípios e procedimentos. 12. ed. Campinas, SP: Pontes

Editores, 2015.

PIMENTA, Selma Garrido. Saberes pedagógicos e atividade docente. 3. ed. São Paulo: Cortez, 2002.

SOBRAL, Francisco José M. Retrospectiva histórica do ensino agrícola no Brasil. Revista Brasileira da Educação Profissional e Tecnológica, Brasília, MEC, SETEC, v. 2, n. 2, p. 79-95, nov. 2009.

TARDIF, Maurice, Saberes profissionais dos professores e conhecimentos universitários. Elementos para uma epistemologia da prática profissional dos professores e suas conseqüências em relação à formação para o magistério. Revista Brasileira de Educação, n. 13, p. 5-24, 2002.

VALLE, Luiza Elena Leite Ribeiro do. A aprendizagem na educação de crianças e adolescentes. Rio de Janeiro: Wak Editora, 2015.

Recebido em: 27/08/2018

Aprovado em: 18/04/2019

Maria Rita Barbosa de Sousa é Mestre em Educação pela Universidade Federal do Piauí; membro do Núcleo Interdisciplinar de Pesquisa em Práticas Curriculares e Formação de profissionais da Educação (NIPPC) e Técnica Administrativa no Cargo de Pedagoga da Universidade Federal do Piauí (UFPI), lotada no Colégio Técnico de Teresina (CTT) onde implantou e executa o Serviço de Orientação Pedagógica (S.O.P) e Coordena a Unidade de Apoio Pedagógico, como também membro do Programa de Assistência Estudantil do Colégio Técnico de Teresina (P.A.E).e-mail: m_rita@ufpi.edu.br

Condomínio Dom Avelar Brandão Vilela. № 64.018-901, Bl.18, Ap.104 - Bairro Tabuleta - Teresina Piauí - Telefone: (86) 99816-0786 
Maria da Glória Carvalho Moura é Doutora em Educação pela Universidade Federal do Rio Grande do Norte. Mestre em Educação pela Universidade Federal do Piauí. Professora Associada do Centro de Ciências da Educação/Departamento de Métodos e Técnicas de Ensino, da Universidade Federal do Piaú, lotada no Departamento de Métodos e Técnicas de Ensino Professora Permanente do Programa de Mestrado em Educação (UFPI/CCE /DMTE/PPGEd). Foi Pró-Reitora de Extensão, no período 2008/2013. É Membro do Comitê de Ética em Pesquisa (CEP); Coordenadora do Núcleo Interdisciplinar de Pesquisa em Práticas Curriculares e Formação de profissionais da Educação - NIPPC; Coordenadora do Comitê Gestor Institucional de Formação Inicial e Continuada de Profissionais da Educação Básica. e-mail: glorinha_m@yahoo. com.br

Rua Picos 3217 - Bairro Piçarra - CEP 64.016-280 - Teresina Piauí - Telefone: (86) 99986-4564 